\title{
Sustainable supply chain network design
}

\author{
Amir M. Fathollahi-Fard ${ }^{1} \cdot$ Maxim A. Dulebenets $^{2} \cdot$ Guangdong Tian $^{3} \cdot$ Mostafa Hajiaghaei-Keshteli $^{4}$
}

(c) The Author(s), under exclusive licence to Springer-Verlag GmbH Germany, part of Springer Nature 2022

Nowadays, there is a great of interest in supply chains, production and operations systems based on the sustainable development goals. In this special issue entitled "Sustainable Supply Chain Network Design" of the journal of Environmental Science and Pollution Research, we received many papers in the areas of facility location, production scheduling, inventory and stock levels and capacities, supply and delivery channels, transportation mode and routing activities, etc. from September 1, 2020, to December 31, 2020. In particular, more than 57 submissions were evaluated, and most of these submissions fell into the aforementioned research areas of the special issue. Among them, 20 papers were accepted for publication in this journal after the required revisions were made by the authors (i.e., the average acceptance rate was 35\%).

Due to importance of Supply Chain Network Design (SCND) in today's economy and recent advances and technologies related to current trends like blockchain, Internet of

Responsible Editor: Philippe Garrigues

Amir M. Fathollahi-Fard

amirmohammad.fathollahifard.1@ens.etsmtl.ca

Maxim A. Dulebenets

mdulebenets@eng.famu.fsu.edu

Guangdong Tian

tiangd2013@163.com

Mostafa Hajiaghaei-Keshteli

mostafahaji@tec.mx

1 Department of Electrical Engineering, École de Technologie Supérieure, University of Quebec, 1100 Notre-Dame St. W, Montreal, Quebec, Canada

2 Department of Civil \& Environmental Engineering, College of Engineering, Florida A\&M University-Florida State University (FAMU-FSU), 2525 Pottsdamer Street, Building A, Suite A124, Tallahassee, FL 32310-6046, USA

3 School of Mechanical Engineering, Shandong University, Jinan 250061, China

4 Tecnologico de Monterrey, Escuela de Ingeniería Y Ciencias, Puebla, Mexico things, and circular economy, the guest editors were selective to make sure that the accepted manuscripts consider these important aspects and satisfy the established journal policies.

In this regard, the accepted papers concentrate of different types of supply chains. For example, Pahlevan et al. (2021) considered the aluminum industry, while the agricultural industry was evaluated in Nasr et al. (2021) and Fallahpour et al. (2021). The nexus and industrial applications were studied by Molajou et al. (2021) and Li et al. (2021), respectively.

To evaluate resiliency in this area, the disasters like earthquakes and COVID-19 pandemic in supply chain management were studied by Beiki et al. (2021) and Shahed et al. (2021), respectively. It goes without saying that the environmental sustainability has been receiving a lot of attention from the community and was highly studied in this special issue. For example, the carbon management in supply chains was studied by Soleimani et al. (2021), Tavana et al. (2021), and Mao et al. (2021). The energy consumption and other environmental pollution factors were studied in Parast et al. (2021); Yuan and Wu (2021), Karimi et al. (2021), and Liang et al. (2021).

In addition, the role of artificial intelligence and machine learning algorithms is significant in the supply chain management. The machine learning algorithms and blockchain technologies in this research area were studied by Amini et al. (2021) and Moosavi et al. (2021), respectively. Finally, optimization was the heart of this special issue, and many studies were devoted to new practical optimization models for the area of sustainable supply chain management (Li et al. 2021b; Shabbir et al.2021; Zhao et al. 2021; Shang et al. 2021).

In conclusion, we tried our best to cover some of the major aspects of the topic and deliver outstanding papers in this area to adequately contribute to the existing literature and fill out some of the critical gaps in the state-of-the-art. At the end, we would like to express our gratitude to the editorial board of the journal, especially Prof. Philippe Garrigues, for giving us this great opportunity, to the reviewers, to the authors, and to all the editorial team members who helped us in this long journey. 


\section{References}

Amini MH, Arab M, Faramarz MG, Ghazikhani A, Gheibi M (2021) Presenting a soft sensor for monitoring and controlling well health and pump performance using machine learning, statistical analysis, and Petri net modeling. Environ Sci Pollut Res :1-17. https:// doi.org/10.1007/s11356-021-12643-0

Beiki H, Seyedhosseini SM, Mihardjo LW, Seyedaliakbar SM (2021) Multiobjective location-routing problem of relief commodities with reliability. Environ Sci Pollut Res: 1-10. https://doi.org/10. 1007/s11356-020-11891-w

Fallahpour A, Nayeri S, Sheikhalishahi M, Wong KY, Tian G, Fathollahi-Fard AM (2021) A hyper-hybrid fuzzy decision-making framework for the sustainable-resilient supplier selection problem: a case study of Malaysian Palm oil industry. Environ Sci Pollut Res :1-21. https://doi.org/10.1007/s11356-021-12491-y

Karimi SK, Naini SGJ, Sadjadi SJ (2021) An integration of environmental awareness into flexible supply chains: a trade-off between costs and environmental pollution. Environ Sci Pollut Res :1-11. https://doi.org/10.1007/s11356-021-13454-z

Li Z, Xie C, Peng P, Gao X, Wan Q (2021b) Multi-objective locationscale optimization model and solution methods for large-scale emergency rescue resources. Environ Sci Pollut Res :1-14. https:// doi.org/10.1007/s11356-021-12753-9

Liang P, Fu Y, Ni S, Zheng B (2021) Modeling and optimization for noise-aversion and energy-awareness disassembly sequence planning problems in reverse supply chain. Environ Sci Pollut Res :1-13. https://doi.org/10.1007/s11356-021-14124-w

Mao J, Sun Q, Ma C, Tang M (2021) Site selection of straw collection and storage facilities considering carbon emission reduction. Environ Sci Pollut Res :1-17. https://doi.org/10.1007/ s11356-021-15581-z

Moosavi J, Naeni LM, Fathollahi-Fard AM, Fiore U (2021) Blockchain in supply chain management: a review, bibliometric, and network analysis. Environ Sci Pollut Res :1-15. https://doi.org/10.1007/ s11356-021-13094-3

Molajou A, Afshar A, Khosravi M, Soleimanian E, Vahabzadeh M, Variani HA (2021) A new paradigm of water, food, and energy nexus. Environ Sci Pollut Res :1-11. https://doi.org/10.1007/ s11356-021-13034-1

Nasr N, Niaki STA, Kashan AH, Seifbarghy M (2021) An efficient solution method for an agri-fresh food supply chain: hybridization of Lagrangian relaxation and genetic algorithm. Environ Sci Pollut Res:1-19. https://doi.org/10.1007/s11356-021-13718-8

Pahlevan SM, Hosseini SMS, Goli A (2021) Sustainable supply chain network design using products' life cycle in the aluminum industry. Environ Sci Pollut Res :1-25. https://doi.org/10.1007/ s11356-020-12150-8

Parast ZZD, Haleh H, Darestani SA, Amin-Tahmasbi H (2021) Green reverse supply chain network design considering location-routing-inventory decisions with simultaneous pickup and delivery. Environ Sci Pollut Res :1-22. https://doi.org/10.1007/ s11356-021-13770-4

Shabbir MS, Mahmood A, Setiawan R, Nasirin C, Rusdiyanto R, Gazali G, Arshad MA,Khan S, Batool F (2021) Closed-loop supply chain network design with sustainability and resiliency criteria. Environ Sci Pollut Res :1-16. https://doi.org/10.1007/s11356-021-12980-0

Shahed KS, Azeem A, Ali SM, Moktadir MA (2021) A supply chain disruption risk mitigation model to manage COVID-19 pandemic risk. Environ Sci Pollut Res :1-16. https://doi.org/10.1007/ s11356-020-12289-4

Shang W, Teng L, Yang JB (2021) Optimization of competitive supply chains with retailers' horizontal cooperation and consumers' green preference. Environ Sci Pollut Res :1-22. https://doi.org/10.1007/ s11356-021-14192-y
Soleimani H, Mohammadi M, Fadaki M, Mirzapour Al-e-hashem SMJ (2021) Carbon-efficient closed-loop supply chain network: an integrated modeling approach under uncertainty. Environ Sci Pollut Res :1-16. https://doi.org/10.1007/s11356-021-15100-0

Tavana M, Tohidi H, Alimohammadi M, Lesansalmasi R (2021) A location-inventory-routing model for green supply chains with low-carbon emissions under uncertainty. Environ Sci Pollut Res :1-13. https://doi.org/10.1007/s11356-021-13815-8

Yuan KS, Wu TJ (2021) Environmental stressors and well-being on middle-aged and elderly people: the mediating role of outdoor leisure behaviour and place attachment. Environ Sci Pollut Res :1-10. https://doi.org/10.1007/s11356-021-13244-7

Zhao J, Xue Z, Li T, Ping J, Peng S (2021) An energy and time prediction model for remanufacturing process using graphical evaluation and review technique (GERT) with multivariant uncertainties. Environ Sci Pollut Res :1-13. https://doi.org/10.1007/ s11356-021-13438-z

Publisher's note Springer Nature remains neutral with regard to jurisdictional claims in published maps and institutional affiliations.

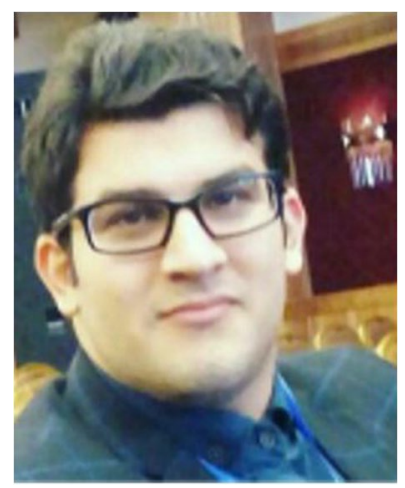

Amir M. Fathollahi-Fard is a Research Associate in the Department of Electrical Engineering at École de Technologie Supérieure, University of Quebec (Montreal, Quebec, Canada). He earned his B.Sc. and M.Sc. degrees from the University of Science and Technology of Mazandaran (Behshahr, Mazandaran, Iran) and a Ph.D. degree in Industrial Engineering from the Amirkabir University of Technology (Tehran, Iran). His research interests include, but are not limited to, supply chain management, health care systems, sustainable logistics and production management, optimization algorithms, heuristics, and metaheuristics. Dr. Fathollahi-Fard published more than 50 papers in high-ranked journals, such as Journal of Cleaner Production, Computers \& Industrial Engineering, Information Sciences, Applied Soft Computing, Expert Systems with Applications, Engineering Applications of Artificial Intelligence, Soft Computing, and others.

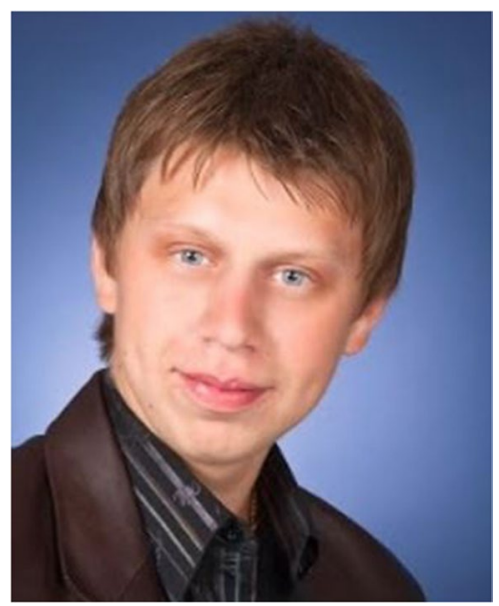

Maxim A. Dulebenets is an Assistant Professor in the Department of Civil \& Environmental Engineering at Florida A\&M University-Florida State University (FAMUFSU) College of Engineering. Dr. Dulebenets holds B.S. and M.Sc. degrees in Railway Construction from the Moscow State University of Railroad Engineering (Moscow, Russia), and M.Sc. and Ph.D. degrees from the University of Memphis (Memphis, $\mathrm{TN}$, USA) in Civil 
Engineering with concentration in Transportation. His research interests include, but are not limited to, operations and research, simulation modeling, optimization, liner shipping scheduling, evolutionary computation, metaheuristics, and transportation engineering. Dr. Dulebenets serves as a referee for more than 100 international journals. The outcomes of his research have been published in leading international journals, including International Journal of Production Economics, Information Sciences, IEEE Transactions on Intelligent Transportation Systems, Advanced Engineering Informatics, and Reliability Engineering \& System Safety. Dr. Dulebenets is actively involved in activities of more than 10 Standing Committees of the Transportation Research Board (TRB) of the National Academies of Sciences, Engineering, and Medicine. He is an Invited Member of the TRB Standing Committee on International Trade and Transportation (AT020). Dr. Dulebenets is an Affiliated Member of the IEEE and INFORMS Optimization Society.

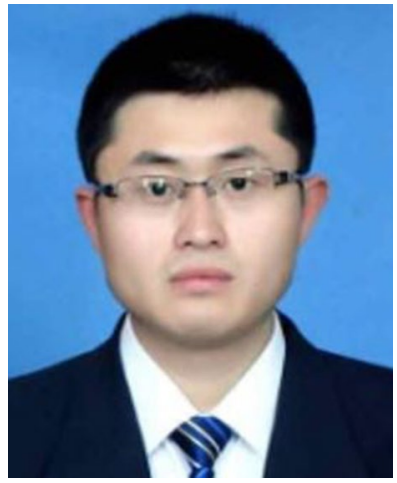

Guangdong Tian received the B.S. degree in vehicle engineering from Shandong University of Technology, Zibo, China, in 2007, the M.S. and Ph.D. degrees in automobile application engineering from Jilin University, Changchun, China, in 2009 and 2012, respectively. He is currently a Professor at the School of Mechanical Engineering, Shandong University, China and Founding member of Sustainable Production and Service Automation in IEEE Robotics and Automation Society. $\mathrm{He}$ invited to organize several conferences and service a session chair, e.g., ICAMechS 2015 and CASE 2016. His research focuses on remanufacturing and green manufacturing, green logistics and transportation, intelligent inspection and repair of automotive, decision making and intelligent optimization. He has published over 100 journal and conference proceedings papers in the above research areas including IEEE Trans. Autom. Sci. Eng., IEEE Trans. Cybernetics and IEEE-ACM Trans. Comput. BI. In addition, he serves as a frequent reviewer for more than 40 international journals including IEEE Trans. Autom. Sci. Eng., IEEE Trans. Syst., Man, Cybern., Part A, and Asian J. Control. He is listed in Marquis Who's Who in the World, 30th Edition, 2013.

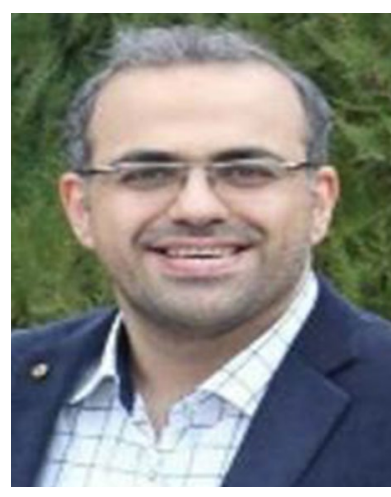

Mostafa Hajiaghaei-Keshteli , was born and raised in Babol, Iran. He earned his B.Sc. from Iran University of Science \& Technology, Tehran, Iran (2004); M.Sc. from University of Science \& Culture, Tehran, Iran (2006); and Ph.D. from Amirkabir University of Technology (Tehran-Polytechnic), Tehran, Iran (2012); all in Industrial Engineering. He is a distinguished research professor at the Department of Industrial Engineering, School of Engineering and Science, Tecnológico de

Monterrey, Puebla Campus, Mexico. He is the founder and head of the research department at the Center of Sustainable and Smart Logistics (CSSL) and a member of the Optimization and Data Science research center. The main focus of his research is in the area of Supply Chain Network, Transportation and Metaheuristics. 